\title{
ANALYSIS OF THE KNOWLEDGE AND AWARENESS REGARDING ANAESTHESIOLOGY AMONG UNDERGRADUATE MEDICAL STUDENTS IN A GOVERNMENT MEDICAL COLLEGE
}

\author{
Vandana Chugh', Nidhi Prabha Sehgal2, Abrar Ahad Chawdhary ${ }^{3}$
}

${ }^{1}$ Specialist, Department of anaesthesia, Dr. Babasaheb Ambedkar Hospital and Medical College, Rohini, Delhi, India.

${ }^{2}$ Specialist, Department of anaesthesia, Dr. Babasaheb Ambedkar Hospital and Medical College, Rohini, Delhi, India.

${ }^{3}$ Senior Resident, Specialist, Department of anaesthesia, Dr. Babasaheb Ambedkar Hospital and Medical College, Rohini, Delhi, India.

ABSTRACT

\section{BACKGROUND}

Anaesthesiologists play a crucial role in patient management, but their contribution remains unrecognized as they are always behind the scenes. This has led to a lack of awareness and knowledge of anaesthesia among public and medical students. This study was conducted to find out knowledge and awareness of anaesthesia speciality among undergraduate medical students. The study also aimed to highlight the need for increasing the clinical exposure of medical students in speciality of anaesthesiology.

\section{MATERIALS AND METHODS}

This was a questionnaire based cross sectional study where 86 medical students completed a questionnaire of 12 items. The questionnaire was divided into four parts-

1. Demographic details and career choice.

2. Knowledge of students regarding role of anaesthesiologist.

3. Knowledge of students regarding role of anaesthesiologist in hospital activities.

4. Knowledge of students regarding clinical anaesthesia.

Results were calculated in percentage format.

\section{RESULTS}

The study showed that undergraduate medical students (preclinical batches) lacked knowledge of anaesthesia, few were not aware that anaesthesiologist is a doctor and majority of students were not aware about types of anaesthesia and preoperative fasting.

\section{CONCLUSION}

It was concluded that students lacked knowledge of anaesthesia and effective measures need to be taken to increase the awareness and knowledge of anaesthesia among undergraduate students. This could be accomplished by designing an attractive clinical curriculum highlighting the glamourous aspect of this speciality (management of chronic pain and exposure to intensive care units) and considering the possibility of including anaesthesiology as a separate subject in undergraduate syllabus.

\section{KEY WORDS}

Knowledge, Medical, Student, Anaesthesiology.

HOW TO CITE THIS ARTICLE: Chugh V, Sehgal NP, Chawdhary AA. Analysis of the knowledge and awareness regarding anaesthesiology among undergraduate medical students in a government medical college. J. Evolution Med. Dent. Sci. 2018;7(53): 5614-5617, DOI: $10.14260 /$ jemds/2018/1242

\section{BACKGROUND}

The speciality of anaesthesiology has evolved tremendously during the last thirty years. Present day anaesthesia is safe and advanced due to introduction of new drugs, improvement in technology and advent of latest anaesthesia workstations. The spectrum of anaesthesiology has broadened, today Anaesthesiologists are not confined to operative rooms but are also catering to intensive care services, chronic pain management and palliative care. In spite of this, anaesthesiology was not first choice of medical undergraduates in a study conducted in $2018 .{ }^{1}$

'Financial or Other Competing Interest': None.

Submission 09-12-2018, Peer Review 22-12-2018,

Acceptance 24-12-2018, Published 31-12-2018.

Corresponding Author:

Dr. Nidhi Prabha Sehgal,

G 117, New Saraswati CGHS Society,

Plot No. 26/1, Sector 9, Rohini,

Delhi-110085, India.

E-mail: doc_nidhi@rediffmail.com

DOI: $10.14260 /$ jemds $/ 2018 / 1242$
Medical students and common man seem to be less aware about speciality of anaesthesiology as compared to other medical fields. A substantial amount of research has revealed poor awareness of anaesthesiology among doctors, interns, medical/dental students, and paramedics.2,3,4 Studies have also revealed that medical students find anaesthesiology as uninteresting and less glamourous. 5

Thus, this study was conducted with the aim of finding out the awareness and knowledge of undergraduate medical students (Preclinical batches) regarding anaesthesiology as a speciality, as a career choice, different roles of Anaesthesiologists in operative rooms and hospital. The results might serve to devise an effective and attractive curriculum for medical students for their clinical postings in anaesthesiology. The results might also serve to highlight the need to reform the existing schedule of anaesthesiology postings in terms of number of hours of anaesthesiology teaching and including anaesthesiology as a separate subject in undergraduate syllabus. 


\section{MATERIALS AND METHODS}

A cross sectional study was conducted in a Government Medical College, Delhi. The study was conducted in a questionnaire format containing 12 questions pertaining to demographic details, awareness and knowledge towards the speciality of anaesthesiology. as a career choice, different roles of Anaesthesiologists in operative rooms and hospital. Eighty-six undergraduate medical students studying in first and second year (Preclinical) session were included in the study. An informed consent was obtained from each participant. The participants not willing to take part in the study were excluded and the ones who participated were assessed according to their responses to the questionnaire.

\section{The questionnaire was divided into four parts-}

1. Demographic details and career choice.

2. Knowledge of students regarding role of Anaesthesiologist.

3. Knowledge of students regarding role of Anaesthesiologist in hospital activities.

4. Knowledge of students regarding Clinical anaesthesia.

Results were calculated in percentage format.

\section{RESULTS}

Eighty-six participants were included in the study and out of these sixty-three were male and twenty-three were females. All the participants were in the age group 17 to 21 years. Sixty percent students opted for anaesthesiology as a as career and forty percent students opted not to choose anaesthesiology.

Knowledge pertaining to role of Anaesthesiologist was inadequate. According to sixteen students (18.6\%) Surgeons decide whether the patient is fit for administering anaesthesia or not and only 59.3\% students knew that Anaesthetist stays with the patient throughout the surgery. (Table. 1) Knowledge about type of anaesthesia was poor as $40.6 \%$ knew only about local anaesthesia, $27.9 \%$ knew about only about general anaesthesia and 8.1\% knew only about regional anaesthesia. Majority of students (60\%) believed that fasting of patients is not requires before administering anaesthesia (Table-2) 73.2\% students knew about the role of Anaesthesiologist in chronic pain management and $72 \%$ were aware of post operative pain management (Table 3). Lowest score obtained was, 3/12 (By one student) and highest score obtained was $11 / 12$ (by one student), None of the student scored $100 \%$ marks and maximum number of students scored marks in the range of 50-74\%. (Table-4)

\begin{tabular}{|c|c|}
\hline Yes & No \\
\hline 52 & 34 \\
\hline $60.4 \%$ & $39.5 \%$ \\
\hline \multicolumn{2}{|c|}{ Career Choice as Anaesthesiology } \\
\hline
\end{tabular}

\section{Who Administers Anaesthesia?}

\begin{tabular}{|l|c|}
\hline 1. Who Administers Anaesthesia? & \\
\hline a) Doctor & $81(94 \%)$ \\
\hline b) Nurse & $2(2.3 \%)$ \\
\hline c) Technician & $3(3.4 \%)$ \\
\hline $\begin{array}{l}\text { 2. Who Decides Patient is Suitable for } \\
\text { Anaesthesia? }\end{array}$ \\
\hline a) Anaesthetist & $62(72 \%)$ \\
\hline b) Surgeon & $16(18.6 \%)$ \\
\hline
\end{tabular}

\begin{tabular}{|c|c|}
\hline c) Technician & 0 \\
\hline d) Do not Know & $08(9.3 \%)$ \\
\hline 3. Person who administers Anaesthesia & \\
\hline a) Stays with the patient throughout surgery & $51(59.3 \%)$ \\
\hline b) Stays at beginning and end of surgery & $14(16.2 \%)$ \\
\hline c) Stays only during beginning & $08(9.3 \%)$ \\
\hline d) Do not know & $13(15 \%)$ \\
\hline \multicolumn{2}{|c|}{ Table 1. Awareness of Role of Anaesthesiologist (Above } \\
\hline
\end{tabular}

\begin{tabular}{|c|c|}
\hline $\begin{array}{l}\text { 1. What are the Types of } \\
\text { Anaesthesia? }\end{array}$ & $\begin{array}{c}\text { *Not answered by } 04 \\
(4.6 \%)\end{array}$ \\
\hline a) General Anaesthesia & $24(27.9 \%)$ \\
\hline b) Regional Anaesthesia & $07(8.1 \%)$ \\
\hline c) Local Anaesthesia & $35(40.6 \%)$ \\
\hline d) All of the Above & $16(18.6 \%)$ \\
\hline $\begin{array}{l}\text { 2. Is Fasting Required Before } \\
\text { Administering Anaesthesia? }\end{array}$ & $\begin{array}{c}{ }^{*} \text { not answered by } 01 \\
(1.1 \%)\end{array}$ \\
\hline a) Yes & $25(29 \%)$ \\
\hline b) No & $60(69.7 \%)$ \\
\hline \multicolumn{2}{|l|}{$\begin{array}{l}\text { 3. Intraoperative Blood is } \\
\text { Transfused by }\end{array}$} \\
\hline a) Surgeon & $20(23.2 \%)$ \\
\hline b) Anaesthetist & $12(13.9 \%)$ \\
\hline c) Nurse & $17(19.7 \%)$ \\
\hline d) Do Not Know & $37(43.02 \%)$ \\
\hline $\begin{array}{l}\text { 4. Post Operative Pain Management } \\
\text { is done by Anaesthetist }\end{array}$ & *not answered by04 \\
\hline a) Yes & $63(72 \%)$ \\
\hline b) No & $19(22 \%)$ \\
\hline
\end{tabular}

\section{what are the types of anaesthesia}

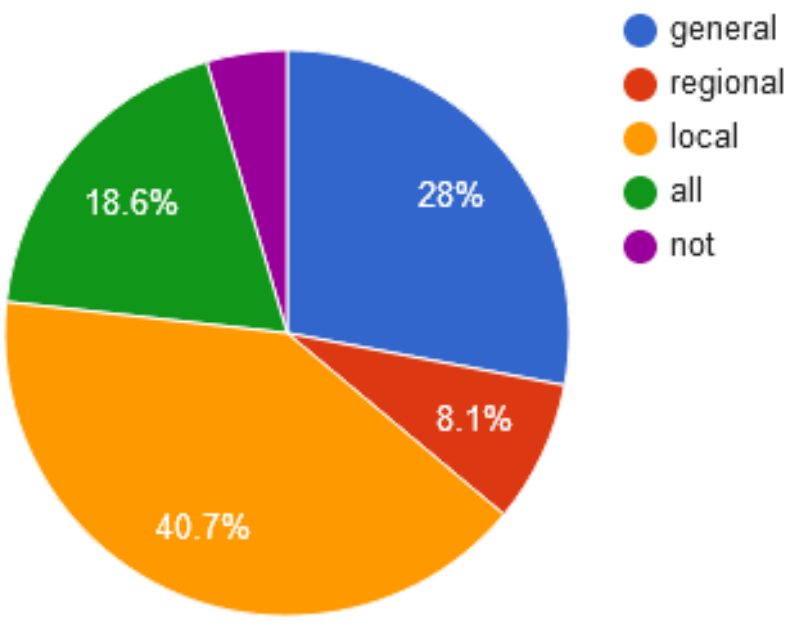

Chart 1. Showing Answer to Types of Anaesthesia

\begin{tabular}{|c|c|}
\hline $\begin{array}{c}\text { 1. Role of Anaesthetist in BLS } \\
\text { (Basic Life Support) }\end{array}$ & \\
\hline a) Yes & $56(65.1 \%)$ \\
\hline b) No & $30(34.8 \%)$ \\
\hline 2. ICU is run by & *not answered by 01 \\
\hline a) Anaesthetist & $14(16 \%)$ \\
\hline b) Physician & $02(2.3 \%)$ \\
\hline c) Pulmonologist & $02(2.3 \%)$ \\
\hline
\end{tabular}




\begin{tabular}{|cl|c|}
\hline d) & Intensivist & $02(2.3 \%)$ \\
\hline e) & All of the Above & $65(75.5 \%)$ \\
\hline 3. Role of anaesthetist is in & ${ }^{*}$ not answered 02 \\
\hline a) & $\begin{array}{l}\text { Difficult Intravenous } \\
\text { Cannulation }\end{array}$ & $06(6.9 \%)$ \\
\hline b) & $\begin{array}{l}\text { Anaphylactic Shock } \\
\text { Management }\end{array}$ & $04(4.6 \%)$ \\
\hline c) $\quad$ Labour Analgesia & $10(11.6 \%)$ \\
\hline d) $\quad$ All of the Above & $64(74.4 \%)$ \\
\hline $\begin{array}{c}\text { 4. Chronic Pain Management is } \\
\text { done by }\end{array}$ & $63(73.2 \%)$ \\
\hline a) $\quad$ Anaesthetist & $04(4.6 \%)$ \\
\hline b) $\quad$ Orthopaedician & $19(22 \%)$ \\
\hline c) $\quad$ Neurosurgeon & Table 3. Role of Anaesthetists in Other Hospital Activities \\
\hline
\end{tabular}

\section{role of anaesthesia in hospital activities}

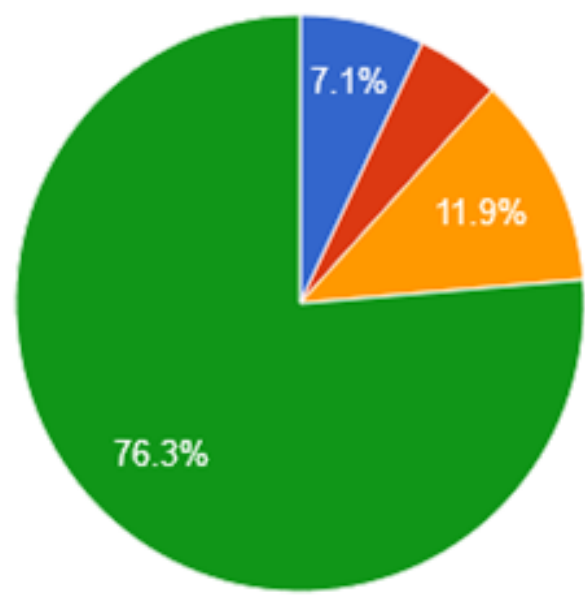

Chart 2. Role of Anaesthesia in Hospital Activities

\begin{tabular}{|c|c|}
\hline Scores (In Percentage) & $\begin{array}{c}\text { Number of Participants and } \\
\text { Percentage }\end{array}$ \\
\hline $0-24 \%$ & 0 \\
\hline $25-49 \%$ & $4(4.65 \%)$ \\
\hline $50-74 \%$ & $54(62.79 \%)$ \\
\hline $75-100 \%$ & $28(32.5 \%)$ \\
\hline \multicolumn{2}{|c|}{ Table 4. Scores } \\
\hline
\end{tabular}

Difficult IV.

Anaphylactic shock.

Labour analgesia.

All of the above.

\section{DISCUSSION}

Anaesthesiologists play a crucial role in patient care but there has been a problem of image of an Anaesthesiologist as a doctor in the eyes of lay man6. In previous studies conducted on public awareness about anaesthesia in India, a large proportion of people were not aware about the person anaesthetizing them.7,8 This was contrary to a study conducted in United Kingdom, in 1994 where 80\% of patients knew that an Anaesthesiologist would administer anaesthesia. ${ }^{9}$

We believe that over the years literate people in India are becoming aware that Anaesthesiologist is a doctor. Mathur et al 10 found that $100 \%$ medical undergraduate students were aware that Anaesthesiologist is a doctor which is similar to our findings. In present study $94 \%$ undergraduate students were aware that Anaesthesiologist is a doctor. As regards role of Anaesthetist in management of post-operative pain, only $13.79 \%$ undergraduate students were aware of Anaesthetists role in post-operative pain (Mathur et al) whereas in present study $72 \%$ undergraduates were aware of the same. In another study ${ }^{2} 35 \%$ medical students (pre-clinical) were aware about Anaesthesiologists role in post-operative period and After these medical students were exposed to clinics their awareness increased and $92.5 \%$.

In the present study we have assessed the knowledge of undergraduate medical students regarding the hospital activities in which Anaesthesiologists are believed to be involved. It was observed in our study that $87 \%$ students were aware that Anaesthesiologists have a role in labour analgesia, $13.9 \%$ students were aware that Anaesthesiologists are involved in intraoperative blood transfusions. Similar results were observed by Aisling et $\mathrm{al}^{2}$ in preclinical Irish medical students. They found that $87.5 \% \%$ students are aware about Anaesthesiologists role in labour analgesia and $22.5 \%$ students were aware about intraoperative blood transfusion role of Anaesthesiologists.

Review of literature shows that Medical undergraduate students have found speciality of anaesthesiology as boring 11 uninteresting 5 and lacking patient contact.12 Time and again studies have been conducted to explore if medical students want to pursue anaesthesiology as their career ${ }^{1,13}$ and factors influencing career choice in anaesthesiology ${ }^{14}$ Patil et al found that $38,3 \%$ interns in a tertiary health centre wanted to pursue anaesthesiology as post graduate course. Similar result was found by Aisling et al where $30 \%$ medical students in clinical batches opted for anaesthesiology as a career. In present study $60.4 \%$ opted for anaesthesiology as a career. Knowledge regarding clinical aspect of anaesthesiology among the medical students was limited according to present study. Students had least knowledge about regional anaesthesia and majority of students answered that fasting of patients is not required before administering anaesthesia.

\section{CONCLUSION}

Undergraduate medical students are lacking basic knowledge of anaesthesiology. Most of the students were not aware about preoperative fasting and types of anaesthesia. It is recommended that positive and glamourous aspects of our speciality should be highlighted among undergraduates. An attractive clinical teaching curriculum should be framed for undergraduate medical students, there should be an increase in number of teaching hours in anaesthesiology clinics and anaesthesiology should be taught as a separate subject in undergraduate syllabus. This will help more and more students opt for anaesthesiology as a career choice and give a boost to our numbers on national front.

\section{REFERENCES}

[1] Alkhilaiwi RM, Alatassi A, Almohawis AH, et al. Medical students' attitude towards anaesthesia as a future career. Saudi J Anaesth 2018;12(2):215-9.

[2] Aisling S, Stephen M, Gabriella I. Irish medical students' knowledge and perception of anaesthesia. Education in Medicine Journal 2013;5(2):83-8. 
[3] Patil V, Savant P, Patwardhan K. Analysis of the knowledge, perception and awareness regarding the scope of anaesthesia in interns in a tertiary health centre. International Journal of Scientific Research 2017;6(10):17-9.

[4] Bhattarai B, Kandel S, Adhikari N. Perception about the role of anaesthesia and anaesthesiologists among the paramedical staffs: perspective from a medical college in Nepal. Kathmandu, University Medical Journal (KUMJ) 2012;10(38):51-4.

[5] Nwasor EO. Perceptions of final-year medical students about choice of anaesthesia as a specialty. Nigerian Journal of Medicine 2010;19(2):208-13.

[6] Armitage EN. The public image of the speciality [letter]. anaesthesia 1978;33(1):64-5.

[7] Vandam LD. American Society of Anaesthesiologists Rovenstine lecture-1979: anaesthesiologists as clinicians. anaesthesiology 1980;53(1):40-8.

[8] Chew ST, Tan T, Tan SS, et al. A survey of patients' knowledge of Anaesthetists and perioperative care. Singapore Med J 1998;39(9):399-402.
[9] Swinhoe CF, Groves ER. Patients' knowledge of anaesthetic practice and role of anaesthetists. anaesthesia 1994;49(2):165-6.

[10] Mathur SK, Dube SK, Jain S. Knowledge about anaesthesia and anaesthesiologist among general population in India. Indian J Anaesth 2009;53(2):17986.

[11] Akinyemi 00, Soyannwo AO. The choice of anaesthesia as a career by undergraduates in a developing country. anaesthesia 1980;35(7):712-5.

[12] Khan FA, Hamdani GA. Factors influencing the choice of anesthesia as a career in a developing country. Middle East J Anesthesiol 2007;19(1):149-57.

[13] Saigal P, Takemura Y, Nishiue T, et al. Factors considered by medical students when formulating their speciality preference in Japan: findings from a qualitative study. BMC Med Educ 2007;7:31.

[14] Tyagi A, Kumar S, Sethi AK, et al. Factors influencing career choice in anaesthesiology. Indian J Anaesth 2012;56(4):342-7. 